\title{
Ambient Ozone as a Risk Factor for ED Visits for Cellulitis
}

\author{
Mieczysław Szyszkowicz ${ }^{1}$, Eugeniusz Porada ${ }^{2}$, Gilaad G. Kaplan ${ }^{3}$ \& Eric Grafstein ${ }^{4}$ \\ ${ }^{1}$ Health Canada, Population Studies Division, 269 Laurier Avenue, Ottawa, Canada \\ ${ }^{2}$ An Independent Consultant \\ ${ }^{3}$ Departments of Medicine and Community Health Sciences, University of Calgary, Calgary, AB, Canada \\ ${ }^{4}$ Department of Emergency Medicine, Providence Health Care and St Paul's Hospital,Vancouver, BC, Canada \\ Correspondence: Mieczysław Szyszkowicz, Health Canada, Population Studies Division, 269 Laurier Avenue, \\ Ottawa, K1A 0K9, Canada. Tel: 1-613-946-3542. E-mail: mietek.szyszkowicz@hc-sc.gc.ca
}

Received: November 23, 2011 Accepted: December 9, 2011 Online Published: June 18, 2012

doi:10.5539/ep.v1n2p105 URL: http://dx.doi.org/10.5539/ep.v1n2p105

\begin{abstract}
Ambient air pollution and weather conditions may affect the number of daily emergency department (ED) visits for skin bacterial infections. The aim of this study was to assess the potential relationship between the odds of an ED visit for cellulitis and the concentration of ambient ozone (O3). The data employed in the study covered ED visits for cellulitis at a Vancouver hospital in the period of January 1999 to February 2003 (1520 days, $\mathrm{N}=$ 9,857). A conditional logistic regression model was built to estimate odds ratios (OR) and their $95 \%$ confidence intervals $(95 \% \mathrm{CI})$. The model was adjusted for temperature and humidity. The results are reported for one interquartile range (IQR) of ozone concentrations $(\mathrm{IQR}=10.9 \mathrm{ppb})$. An increase by one IQR in daily ozone concentrations lagged by 3 days was significantly associated with an increase in the odds of ED visit for cellulites: among male patients $\mathrm{OR}=1.06(95 \% \mathrm{CI}$ : 1.01-1.13) and among female patients in the warm period (April-September) OR=1.20 (95\% CI: 1.06-1.48). Patients aged 50 or less showed increased odds. Some cases of cellulitis may be associated with exposure to ambient ground-level ozone.
\end{abstract}

Keywords: cellulites, emergency department visit, ozone, odds ratio, skin, urban

\section{Introduction}

Air pollution is a recognized risk factor for multiple health conditions presenting to emergency departments (ED) (Villeneuve et al., 2007; Stieb et al., 2009). A hypothesis that some skin conditions are exacerbated by exposure to ambient ground-level ozone has already been investigated, and epidemiological relationships between these conditions and ambient ozone concentration were observed (Larrieu et al., 2009; Szyszkowicz et al., 2010; Xu et al., 2011). Skin infections, cellulitis in particular, stand out as the most frequent complaint of ED patients in a number of Canadian hospitals (e.g., in Vancouver), motivating research in the epidemiology and pathology of skin infectious diseases. The question arises as to how the known mechanism of ozone oxidative stress to nucleic acids, proteins, and lipids within the cellular membrane (Fridovich, 1978), known in some detail in the case of targets in the cardiorespiratory system (Pyror, 1993), applies to targets in the epidermis as well, keratinocytes in particular.

Cellulitis is an acute inflammation of the epidermis (subcutaneous and connective tissues of the skin), and can be caused by infection with streptococcus aureus, staphylococcus, and other bacteria. The incubation period varies, depending on the type of bacteria causing the cellulitis, and can be less than 24 hours or several days. Deep and rapidly spreading infections may develop into life-threatening emergencies.

Microbiological research recognizes susceptibility to structural skin damages as a factor in skin susceptibility to cellulitis infection. Structural damage seems to be required in order for the responsible bacteria to penetrate the first-line-of-defense mechanisms in the skin. The issue appears in animal studies (Olkowski et al., 2005), but seems to be of importance when human skin infections are investigated. Cunningham (Cunningham, 2000) writes "In skin attachment and colonization by group A streptococci, a site of previous damage may be important in overcoming the dermal barrier." However, cellulitis quite often develops in skin that appears perfectly normal (Abrahamian et al., 2008), as if only the protective properties of skin and its relative impenetrability were damaged. There are cues that exposure to ambient ozone may result in oxidative stress to the skin (Thiele et al., 
1997), damaging skin lipids (Camhi et al., 1997; Wisthaler \& Weschler, 1995) and keratinocytes (Zuliani et al., 2004), and rendering the skin a conductive environment for colonization by bacteria. Essentially, the oxidative stress would involve disturbing the oxidant-antioxidant balance such that it is advantageous to the microbe (Gibson et al., 1996; Cunningham, 2000), damaging skin cells and impairing skin immunity (Katsumi et al., 2001). The pathogen itself seems to better endure the ozone-induced oxidation: the streptococci are known to be among bacteria that are the most resistant to ozone sanitary oxidizing (US EPA, 1999).

Still, both questions how biochemical parameters of skin are modified by different ozone concentrations and how effectively the antioxidant system of human skin protects against ozone reactivity remain untouched, to our knowledge. In particular, it is not understood why ozone appears less reactive in the case of older people (they are less sensitive to ozone exposure (Devlin et al., 1997). Also, on the epidemiological front, no studies have been performed to date. This study is the first to link ozone exposure to cellulitis cases.

\section{Materials and methods}

\subsection{Study Population}

The study population consisted of patients serviced by St. Paul's hospital located in downtown Vancouver, British Columbia, between January 1, 1999 and February 28, 2003. During that period the hospital serviced approximately 53,000 patients per year, with an admission rate of $15 \%$. Full-time emergency physicians and hospital staff recorded discharge diagnoses in ED charts following an established list of diagnosis, which included "Cellulitis". Among the total of 194,443 ED visits occurring in the study period (1520 days), 9,857 were classified as cellulitis cases ( $5 \%$ of all visits). Cellulitis emerged as the most frequent diagnosis, followed by "Abdominal Pain NYD", $N=7,523$. The ED charts allowed us to create the daily counts of ED visits for cellulitis for all days in the study period.

\subsection{Environmental Data and Exposure}

The average ozone level in Vancouver and surrounding region, the Lower Fraser Valley, is among the lowest in Canada (DAWG, 1997; Pryor et al., 1995). In the period 1980 - 1993, Vancouver registered the fewest daily averages of ozone concentration above $82 \mathrm{ppb}$, which is the threshold for acceptable air quality in Canada. For instance, in Toronto, Ontario, daily ground-level ozone exceeding $82 \mathrm{ppb}$ is 13 times more frequent. Also, the average ozone level was among the lowest in Canada. Fixed monitoring stations in Vancouver recorded the lowest mean and maximum ozone levels in the country during the months of October through February $(<10$ ppb). The month of May showed the highest average concentration, $\sim 20 \mathrm{ppb}$. However, the spatial variability of ozone levels is much greater than in other Canadian big cities. Mostly suburban areas had higher ozone levels and were showing larger-range variation than that in downtown Vancouver, where the St. Paul's hospital is located.

In the study period (1999 - 2003), the average ozone concentration was slightly higher, but never exceeding the acceptable value of $82 \mathrm{ppb}$ : the average ozone level in the months of October through February equaled (in ppb) $10.4(\min =0.7, \max =33.6)$, while the May average was $22.6(\min =10.1, \max =37.0)$. The all-period mean was 14.2 , with a standard deviation (SD) equal to 7.4 , and an interquartile range (IQR, IQR $=75$ th percentile 25th percentile) equal to 10.9 , and $\max =38.0$.

The data were supplied by Environment Canada in the form of hourly O3 concentration measurements obtained from fixed continuous monitoring stations in the greater Vancouver area. During the 4-year study period the number of monitoring stations ranged from 4 to 11. The distance of a station from the hospital varied between 3 and 43 kilometers. We calculated the daily ozone concentrations by averaging hourly data over 24 -hour periods across the monitoring stations.

Also, Environment Canada supplied hourly data on relative humidity and temperature (dry bulb) for the city of Vancouver. The city, and the Lower Fraser Valley, experienced relatively mild temperatures and relative humidity, along with large amounts of precipitation. The mean temperature (in degrees Celsius) was 7.7, $\mathrm{SD}=11.4$; and the mean relative humidity (in \%) equaled $70.7, \mathrm{SD}=12.5$.

The daily values of these weather parameters, temperature and relative humidity, were calculated by averaging hourly data over 24-hour periods.

We considered the Vancouver ozone daily concentrations to be the short-term recent exposure level for a patient of the St. Paul's hospital, without seeking to establish his/her actual residence.

\subsection{Statistical Analysis}

The case-crossover (CC) technique (Maclure, 1991) was used in this study. When applied to investigations of 
acute adverse health effects triggered by transient (but common to the population) exposure, it is equivalent to the time-series method (Lu and Zeger, 2007). In the CC method, a subject's exposure on the day when it affected $\mathrm{him} / \mathrm{her}$ (i.e., case day) is compared with the exposures on a pre-selected set of days when the subject was not affected (i.e., control days). Two periods of exposure are compared: the case period and the control period. Accepting this level of abstraction, a CC study can be considered a case-control study. The CC routines, based on the daily count of health events and the measurement of daily exposure, estimate the odds of being affected (i.e., seeking ED help afterwards) for two virtual groups of individuals, with one group experiencing a higher one-day exposure than the other. The assumed differential between the exposures, the IQR calculated for daily exposure data, is a conventional unit.

Although the formulations involve conceptual notions, the computations basically perform logistic regression of the daily count (of health events - here, ED visits) for independent variables (here, ozone daily concentrations and weather parameters). Regression coefficients are evaluated on the set of control days and on the set of case days, separately, allowing for the obvious recurrence of observations. The odds ratio is calculated from the two regression coefficients and returned. The ratio, if higher than 1, estimates the relative increase in daily frequency of $\mathrm{ED}$ visits upon an increase in ozone concentration equaling $\mathrm{IQR}=10.9 \mathrm{ppb}$. The absolute increase in frequency is proportional to the actual increase in exposure.

On the use of lagging models' parameters, we considered the day of ED visit as case day. We carried out computations for lags ranging from 0 to 5 days, with lag 0 testing the assumption of the same-day exposure and visit, lag 1-the one-day delay between the exposure and visit, etc.

The control days were selected in proximity to the case day, so the time-invariant or only gradually changing confounders (such as patient's health conditions, seasonal effects) did not vary significantly between the case days and the control days. Furthermore, if day-of-week for controls and case matched, the dow effect was ostensibly controlled for (Janes et al., 2005).

According to well established CC practice, we selected for each case day all the other dow-matched days in the month that included case day; thus, each case was assigned 3 or 4 controls (Janes et al., 2005).

The regression models we constructed incorporated the temperature and relative humidity parameters in a non-linear manner, as natural splines with 3 degrees of freedom. The analysis was performed independently for a continuum of age groups, for both genders, for warm and cold seasons, and necessarily when applying 0- to 5-day lags to the exposure and weather parameters.

The precision of the $\mathrm{CC}$ technique depends more on the variations of the exposure parameter than on the number of observations, as the frequent and transient surges in exposure allow for the most decisive test for exposure-effect links. The flatter the exposure is, the wider the confidence interval of the estimator.

\section{Results}

Males visited the ED with cellulitis 3 times more frequently than did females. The average daily count of visits for male patients was 4.7, and for female patients 1.8 , with a standard deviation of 2.6 and 1.4 , respectively. The daily count attained a maximum of 16 male patients, 8 female patients, and 20 for both sexes combined.

The months of the most frequent visits, July and August, accounted for $20 \%$ of all visits; of this proportion, $68 \%$ were male visitors. In the cold season most visits occurred in January and February, and $76 \%$ of these visits were by male patients.

Table 1 shows the frequencies of ED visits for cellulitis by age group and sex. Almost $30 \%$ of patients were between the ages of 30 and 40 .

Table 2 shows the OR values and $95 \%$ CIs by season and sex, for exposures lagged by 0 to 3 days, and for patients of all ages, contrasted with patients aged 50 or younger (warm season: April-September, cold: October-March). As a rule, the OR is computed per IQR increase in ozone level (IQR $=10.9 \mathrm{ppb})$.

These results are in line with the hypothesis that skin more susceptible to ozone oxidative damage (as shown by dry skin and photo-aged skin) is also more susceptible to cellulitis infection. The results also reflect the diminished responsiveness to ozone in older people. For all-season ED visits, the results became statistically significant when ozone exposure was lagged by 3 days, pointing to a 3-day gap between exposure and ED visit. This is specific to male patients to the degree that, even in the cold season, higher odds for men not older than age 50 were captured. Among women, the chance of an ED visit one day after exposure in the warm season was the highest. 
Table 1. Frequency of ED visits for cellulitis by age group and sex

\begin{tabular}{lllll}
\hline Age group & Visits & $\begin{array}{l}\text { \% of Total } \\
\text { Visits }\end{array}$ & Female & Male \\
\hline $0-19$ & 184 & 1.9 & 93 & 91 \\
$20-29$ & 1,652 & 16.8 & 586 & 1,066 \\
$30-39$ & 2,857 & 29.0 & 687 & 2,170 \\
$40-49$ & 2,505 & 25.4 & 475 & 2,030 \\
$50-59$ & 1,335 & 13.6 & 366 & 969 \\
$60-69$ & 586 & 6.0 & 173 & 413 \\
$70-79$ & 517 & 5.3 & 212 & 305 \\
$80-80+$ & 220 & 2.2 & 95 & 125 \\
\hline Total & 9,857 & 100.0 & 2,688 & 7,169 \\
\hline
\end{tabular}

Table 2. Odds ratios (OR) and their 95\% confidence limits (95\% CI) for ED visits for cellulitis by sex and period (* p-value $<0.05$. ${ }^{\mathrm{a}}$ Upper row: all patients. Lower row: patients under 50 years of age.)

\begin{tabular}{|c|c|c|c|c|c|c|c|}
\hline \multicolumn{2}{|l|}{ Patients: } & \multicolumn{2}{|l|}{ All } & \multicolumn{2}{|l|}{ Male } & \multicolumn{2}{|c|}{ Female } \\
\hline Season & Lag & OR & $95 \% \mathrm{CI}$ & OR & $95 \% \mathrm{CI}$ & OR & $95 \% \mathrm{CI}$ \\
\hline \multirow[t]{8}{*}{ Whole } & 0 & 0.98 & $0.93-1.03$ & 0.97 & $0.91-1.03$ & 1.01 & $0.91-1.13^{\mathrm{a}}$ \\
\hline & & 0.98 & $0.92-1.04$ & 0.96 & $0.89-1.03$ & 1.04 & $0.92-1.18$ \\
\hline & 1 & 1.02 & $0.97-1.08$ & 1.00 & $0.94-1.07$ & 1.07 & $0.96-1.19$ \\
\hline & & 1.03 & $0.96-1.09$ & 1.01 & $0.94-1.08$ & 1.08 & $0.96-1.23$ \\
\hline & 2 & 1.03 & $0.98-1.09$ & 1.01 & $0.95-1.08$ & 1.07 & $0.97-1.19$ \\
\hline & & 1.05 & $0.99-1.12$ & 1.05 & $0.97-1.12$ & 1.06 & $0.94-1.20$ \\
\hline & 3 & $1.07^{*}$ & $1.01-1.13$ & $1.06^{*}$ & $1.00-1.13$ & 1.09 & $0.98-1.21$ \\
\hline & & $1.07^{*}$ & $1.01-1.14$ & $1.08^{*}$ & $1.01-1.16$ & 1.05 & $0.93-1.19$ \\
\hline \multirow[t]{8}{*}{ Warm } & 0 & 1.02 & $0.93-1.11$ & 0.97 & $0.88-1.08$ & 1.14 & $0.96-1.35$ \\
\hline & & 1.03 & $0.93-1.14$ & 0.98 & $0.86-1.10$ & 1.18 & $0.97-1.44$ \\
\hline & 1 & 1.08 & $0.98-1.18$ & 1.01 & $0.91-1.13$ & $1.25^{*}$ & $1.06-1.48$ \\
\hline & & $1.11^{*}$ & $1.00-1.23$ & 1.03 & $0.91-1.16$ & $1.35^{*}$ & $1.10-1.65$ \\
\hline & 2 & 1.04 & $0.95-1.14$ & 1.00 & $0.90-1.12$ & 1.14 & $0.96-1.35$ \\
\hline & & 1.08 & $0.97-1.20$ & 1.04 & $0.92-1.18$ & 1.19 & $0.97-1.45$ \\
\hline & 3 & $1.10^{*}$ & $1.01-1.21$ & 1.06 & $0.95-1.19$ & $1.20^{*}$ & $1.01-1.42$ \\
\hline & & 1.10 & $0.99-1.23$ & 1.05 & $0.93-1.19$ & $1.27^{*}$ & $1.03-1.55$ \\
\hline \multirow[t]{8}{*}{ Cold } & 0 & 0.95 & $0.88-1.02$ & 0.96 & $0.88-1.04$ & 0.93 & $0.81-1.07$ \\
\hline & & 0.95 & $0.87-1.03$ & 0.95 & $0.87-1.05$ & 0.94 & $0.80-1.11$ \\
\hline & 1 & 0.97 & $0.90-1.04$ & 0.99 & $0.91-1.07$ & 0.93 & $0.81-1.07$ \\
\hline & & 0.98 & $0.90-1.06$ & 1.00 & $0.91-1.10$ & 0.90 & $0.76-1.06$ \\
\hline & 2 & 1.01 & $0.95-1.09$ & 1.03 & $0.95-1.11$ & 0.98 & $0.86-1.13$ \\
\hline & & 1.04 & $0.96-1.12$ & 1.07 & $0.98-1.18$ & 0.94 & $0.79-1.11$ \\
\hline & 3 & 1.04 & $0.97-1.11$ & 1.06 & $0.98-1.15$ & 0.97 & $0.85-1.12$ \\
\hline & & 1.06 & $0.97-1.15$ & $1.11^{*}$ & $1.01-1.22$ & 0.90 & $0.76-1.07$ \\
\hline
\end{tabular}




\section{Conclusions}

The site of this study, Vancouver, was selected on the grounds that it showed the highest prevalence of cellulitis among Canadian metropolitan cities. However, Vancouver experiences the lowest frequency of excessive ambient ozone concentrations in Canada. We detected significant effects of ambient ozone exposure on ED visits for cellulitis in the most sensitive groups: patients younger than age 50, male patients in the cold season, and female patients in the warm season. It appears that the manifestations in the warm season could be captured, since the measurements of ozone concentration using fixed monitoring stations better reflected the true exposure: i.e. potential patients are more likely to be outside. The results are similar to those presented in another work on ozone and cellulitis (Szyszkowicz et al., 2010). Also, they run the risk of more extensive skin exposure, due to higher ambient ozone levels in that season, and less skin protection from the exposure. The association of 1-day-old exposure with a subsequent ED visit among women is a finding in line with observations of an increased risk of a medical visit for skin rashes in the days following exposure to ambient air pollution (Larrieu et al., 2009). It appears that UV radiation may be the synergistic factor in the aggravation of acute symptoms of skin inflammation. In fact, an increase in UV-B will result in increased amounts of ground-level ozone and photochemical smog (Wayne, 1991).

Regarding male patients, a positive and significant association between a 3-day lag of the exposure and an ED visit was found. The lag, while reflecting the delay between the exposure and ED visit, also indicates an average time of developing a bacterial skin inflammation.

These findings highlight the need for more studies evaluating the risks of ambient ozone exposure and its potential role in triggering acute skin inflammations in locations where the exposure is above acceptable limits. This may promote individual efforts aimed at preventing cellulitis, and also the development or improvement of air quality programs.

One of the strong aspects of this study is the controlling for temporal trends (long-term effects, seasonal cycle, month-of-year impact) and non-linear meteorological factors (relative humidity and temperature), which otherwise may have confounded the results. UV radiation confounds the results, but the UV-induced oxidative stress shows so close a relationship to ozone-induced oxidation at the biochemical level (see, for example, effects on the human lens (Spector, 1995; Andley et al., 1990; Linetsky et al., 1996)), that the epidemiological research may identify only the involvement of ozone rather than the unambiguous ozone effects.

The CC design has the inherent faculty of controlling for time-independent risk factors (e.g., patients' diabetes) by selecting case controls identical with the cases from the point of view of these permanent aspects. Finally, adequate sample size and study period ensured the statistical power required for evaluation of the odds where they became evident, in comparatively low-exposure scenarios.

The study results should be interpreted in the context of the limitations of the study. Non-differential misclassification of the exposures or the outcomes would have biased our risk estimates towards the null. Regional estimates of $\mathrm{O} 3$ exposure may not have correlated with patient-level exposures prior to visits to the ED. Air pollution data from fixed monitoring sites were averaged; however, monitors that collected environmental data were located far from (up to $43 \mathrm{~km}$ ) St. Paul's hospital. People living in the downtown area would be more likely than those further away to use the hospital; whereas suburban cases of cellulitis may have been seen in other hospitals. (Differences in ozone levels between regions in the Vancouver area, though not large, are more pronounced than in other cities in Canada.) Next, we used the administrative definition of cellulitis in the absence of data specifying internationally accepted codes of diseases. A classification of the severity of cellulitis infections was unavailable as well. Additionally, milder cases of cellultis, adequately controlled with medication, would not appear in the study population. Finally, Vancouver is the site of small variations in ozone levels, which does not provide opportunities to resolve less accentuated effects.

Summarizing, an increase in concentration of ambient ground-level ozone was associated with an increased odds of an emergency department visit for cellulites, particularly among individuals more highly sensitive to ozone. Future epidemiological and basic science studies are necessary to replicate these findings and evaluate the relationship between ozone exposure and cellulitis. This study suggests a novel modifiable risk factor for the development of cellulitis among at-risk populations.

\section{References}

Abrahamian, F. M., Talan, D. A., \& Moran, G. J. (2008). Management of skin and soft-tissue infections in the emergency department. Infect Dis Clin North Am., 22, 89-116. http://dx.doi.org/10.1016/j.idc.2007.12.001

Andley, U. P., Walsh, A., Kochevar, I. E., \& Reddan, J. R. (1990). Effect of ultraviolet-B radiation on protein 
synthesis in cultured lens epithelial cells. Curr Eye Res., 9, 1099-106. http://dx.doi.org/10.3109/02713689008997583

Camhi, S. L. Lee, P., \& Choi, A. M. (1995). The oxidative stress response. Critical Care Medicine (New Horizon), 3, 170-82.

Cunningham, M. W. (2000). Pathogenesis of group a streptococcal infections. Clin Microbiol Rev., 3(3), 470-511.

Data Analysis Working Group. (1997). Ground-level ozone and its precursors, 1980-1993. Canadian Council of Ministers of the Environment. http://dx.doi.org/10.1128/CMR.13.3.470-511.2000

Devlin, R. B., Raub, J. A., \& Folinsbee, L. J. (1997). Health effects of ozone. Sci Med., 8-17.

Fridovich, I. (1978). The biology of oxigene radicals. Science, 201, 875-80. http://dx.doi.org/10.1126/science. 210504

Gibson, C., \& Caparon, M. (1996). Insertional inactivation of sod in Streptococcus pyogenes suggests that prtF is regulated via a superoxide signal. $J$ Bacteriol, $178,4688-95$.

Janes, H., Sheppard, L., \& Lumley, T. (2005). Case-crossover analyses of air pollution exposure data. Referent selection strategies and their implications for bias. Epidemiology, 16(6), 717-726. http://dx.doi.org/10.1097/01.ede.0000181315.18836.9d

Katsumi, M., Kazuko, K., \& Takashi, M. (2001). Impairment of microbial killing and superoxide-producing activities of alveolar macrophages by a low level of ozone. $J$ Health Sci., 47(3), 302-9. http://dx.doi.org/10.1248/jhs.47.302

Larrieu, S., Lefranc, A., Gault, G., Chatignoux, E., Couvy, F., Jouves, B., \& Filleul, L. (2009). Are the short-term effects of air pollution restricted to cardiorespiratory diseases? Am J Epidemiol., 169(10), 1201-1208. http://dx.doi.org/10.1093/aje/kwp032

Linetsky, M., James, H. L., \& Ortwerth, B. J. (1996). The generation of superoxide anion by the UVA irradiation of human lens proteins. Exp Eye Res., 63, 67-74. http://dx.doi.org/10.1006/exer.1996.0092

Lu, Y., \& Zeger, S. L. (2007). On the equivalence of case-crossover and time series methods in environmental epidemiology. Biostatistics, 8(2), 337-44. http://dx.doi.org/10.1093/biostatistics/kx1013

Maclure, M. (1991). The case-crossover design: a method for studying transient effects on the risk of acute events. Am J Epidemiol, 133(2), 144-153.

Olkowski, A. A., Wojnarowicz, C., Chirino-Trejo, M., Wurtz, B. M., \& Kumor, L. (2005). The role of first line of defence mechanisms in the pathogenesis of cellulitis in broiler chickens: skin structural, physiological and cellular response factors. $J$ Vet Medicine, 52(10), http://dx.doi.org/10.1111/j.1439-0442.2005.00768.x

Pryor, S. C., McKendry, I. G., \& Steyn, D. G. (1995). Synoptic-scale meteorological variability and surface ozone mixing ratios in Vancouber, British Columbia. $J$ Appl Met., 34, 1824-33. http://dx.doi.org/10.1175/1520-0450(1995)034\%3C1824:SSMVAS\%3E2.0.CO;2

Pryor, W. A. (1993). Ozone in all its reactive splendor. J Lab Clin Med., 122(5), 483-6.

Spector, A. (1995). Oxidative stress-induced cataract: mechanism of action. FASEB J., 9, 1173-82.

Stieb, D. M. Szyszkowicz, M., Rowe, B. H., \& Leech, J. A. (2009). Air pollution and emergency department visits for cardiac and respiratory conditions: a multi-city time-series analysis. Environ Health, 8, 25. http://dx.doi.org/10.1186/1476-069X-8-25

Szyszkowicz, M., Porada, E., Kaplan, G. G., \& Rowe, B. H. (2010). Ambient ozone and emergency department visits for cellulitis. Int. J. Environ. Res. Public Health, 7, 4078-4088. http://dx.doi.org/10.3390/ijerph7114078

Szyszkowicz, M., Porada, E., Searles, G., \& Rowe, B. H. (2010). Ambient ozone and emergency department visits for skin conditions. Air Qual Atmos Health. http://dx.doi.org/10.1007/s11869-010-0092-5

Thiele, J. J., Podda, M., \& Packer, L. (1997). Tropospheric ozone: an emerging environmental stress to skin. Biol Chem., 378, 1299-1305.

Truscott, R. J. (2005). Age-related nuclear cataract-oxidation is the key. Exp Eye Res., 80, 709-25. http://dx.doi.org/10.1016/j.exer.2004.12.007 
U. S. Environmental Protection Agency. (1999). Guidance Manual: Alternate Disinfectants and Oxidants, April.

Villeneuve, P. J., Chen, L., Rowe, B. H., \& Coates, F. (2007). Outdoor air pollution and emergency department visits for asthma among children and adults: a case-crossover study in northern Alberta, Canada. Environ Health, 6, 40. http://dx.doi.org/10.1186/1476-069X-6-40

Wayne, R. P. (1991). Chemistry of the Atmospheres (2nd ed). Oxford.

Wisthaler, A., \& Weschler, C. J. (2009). Atmospheric Chemistry Special Feature: Reactions of ozone with human skin lipids: Sources of carbonyls, dicarbonyls, and hydroxycarbonyls in indoor air. Proc Natl Acad Sci U S A.

Xu, F., Yan, S., Wu, M., Li, F., Xu, X., Song, W., Zhao, J., Xu, J., \& Kan, H. (2011). Ambient ozone pollution as a risk factor for skin disorders. $B r \quad J$ Dermatol, $165(1), \quad 224-5$. http://dx.doi.org/10.1111/j.1365-2133.2011.10349.x

Zuliani1, T., Denis, V., Layat, C., Noblesse, E., Schnebert, S., Dumas, M., \& Ratinaud, M. H. (2004). Oxidative stress-induced cell death in human epidermal keratinocytes is dependent on their differentiation state. 34th Annual European Society for Dermatological Reasearch, 9-11 September 2004, Vienna, Austria. Abstract 22. 